\title{
Halogen and noble gas compositions near the subduction interface recorded in metamorphic rocks
}

\author{
JIE REN ${ }^{1}$, HIROCHIKA SUMINO ${ }^{1}$, YUI KOUKETSU ${ }^{2}$ AND \\ SIMON RICHARD WALLIS ${ }^{1}$ \\ ${ }^{1}$ The University of Tokyo \\ ${ }^{2}$ Nagoya University \\ Presenting Author: renjie@g.ecc.u-tokyo.ac.jp
}

The distinct elemental and/or isotopic compositions of halogens and noble gases in different reservoirs of subduction system make them good tracers for fluid origin. In this study, we determined the halogen and noble gas compositions in a series of metamorphic rocks that recorded a paleo slab-mantle wedge boundary [1]. Analyzed samples are ultramafic serpentinite (derive from the mantle wedge) and schist (derive from subducted sediment exhumed from up to $30 \mathrm{~km}$ depth) of the Sanbagawa metamorphic belt in central Shikoku, Japan.

A portion of each sample was neutron-irradiated to convert halogens to noble gas isotopes, which have lower detection limits than direct analyses with other methods. The irradiated and unirradiated portions were analyzed by noble gas mass spectrometry to determine halogens and noble gases, respectively.

The halogen compositions of fluids in the serpentinite and schist obtained by crush extraction show relatively high $\mathrm{I} / \mathrm{Cl}$ ratios with stable $\mathrm{Br} / \mathrm{Cl}$ ratios compared with halogens in MORB-mantle or seawater. These features are similar to the data for the nearby Higashi-akaishi mantle wedge peridotite exhumed from $\sim 100 \mathrm{~km}$ depth [2], which are considered to partially preserve the signals of sedimentary pore fluids. In addition, the serpentinite body shows overall decreasing $\mathrm{I} / \mathrm{Cl}$ ratios with increasing distance from the subduction interface. This supports the idea that the original high $\mathrm{I} / \mathrm{Cl}$ fluids were transported along the subduction interface and penetrated upward into the mantle wedge.

The isotopic data of the noble gases are complex. Neon and argon isotopic compositions are almost overwhelmed by the seawater/atmosphere component. Helium shows distinct and diverse ${ }^{3} \mathrm{He} /{ }^{4} \mathrm{He}$ ratios ranging from 0.13 to $88 \mathrm{Ra}$ (Ra denotes atmospheric ${ }^{3} \mathrm{He} /{ }^{4} \mathrm{He}$ ratio), which is likely to be strongly influenced by the cosmic ray, producing ${ }^{3} \mathrm{He}$ preferentially. Nevertheless, a radiogenic ${ }^{3} \mathrm{He} /{ }^{4} \mathrm{He}$ component possibly derived from subducted crust/sediment was identified in the fluids extracted from the serpentinite. This adds support to the idea that the shallow part of mantle wedge has been influenced by addition of volatiles from the subducted slab.

[1] Kawahara et al (2016). Lithos, 254-255.

[2] Sumino et al (2010). EPSL, 163-172. 